\title{
Source Characteristics of the 17 January 1994 Northridge, California, Earthquake from Regional Broadband Modeling
}

\author{
by Xi J. Song, Laura E. Jones, and Donald V. Helmberger
}

\begin{abstract}
Broadband regional records are modeled to determine source mechanism, seismic moment, fault dimension, and rupture directivity for the 17 January 1994 Northridge earthquake. Modeling is done using both theoretical Green's functions (tGf) and empirical Green's functions (eGf). From the theoretical modeling, we obtain a source mechanism with strike $128^{\circ}$, dip $33^{\circ}$, and rake $106^{\circ}$ for the mainshock, using a source estimation algorithm by Zhao and Helmberger (1994). While the fault orientation seems resolvable from regional data, the moment estimation is less reliable due to inadequate synthetic waveform fits to the observed surface waves. This appears to be caused by the combination of propagational effects and fault complexities. Further investigation of the source characteristics is carried out with a new method of using eGf's. As an eGf, we select the 17 January 1994 17:56 GMT aftershock, which occurred near the onset of the mainshock and had a similar source mechanism. The source duration of the mainshock, as seen from the regional surface waves observed at various stations, is obtained by searching for the trapezoidal far-field source-time function for each station that, when convolved with the aftershock data, best simulates the mainshock data. Stations to the north record shorter source durations than stations to the south. Modeling these with theoretical predictions of rupture on a square fault, we constrain the effective fault dimension to be $14 \mathrm{~km}$ with rupture along the direction of the average rake vector. A moment of $(1.4 \pm 0.9) \times 10^{26}$ dyne-cm with a stress drop of $\sim 120$ bars is obtained for the mainshock from our eGf study.
\end{abstract}

\section{Introduction}

Recent advances in seismic acquisition are making it possible to rapidly estimate source parameters of significant earthquakes. The following are typical questions asked by seismologists after a large event such as the Northridge earthquake: (1) Where did it occur and how large was it? (2) What were its fault parameters? (3) Which plane ruptured and in what direction? (4) Should we expect to see surface breakage? Currently, the first two questions are answered by modern seismic arrays shortly after the earthquake. Answering the remaining questions often requires further study. For the Northridge earthquake, however, work was complicated both by propagational effects introduced by the San Fernando Basin and by the loss of a critical TERRAscope station (ISA) to the north (Fig. 1). Loss of records from station ISA made necessary the use of records from stations farther to the north, at much greater epicentral distances than those used in previous modeling studies in southern California (e.g., Dreger and Helmberger, 1991). Thus, given the relatively long, structurally complex paths connecting Northridge to the three distant stations (PKD1, CMB and MLA), we chose to augment our theoretical modeling with an eGf study.
The eGf study was further motivated by the azimuthal variation in absolute timing of the mainshock relative to a nearby aftershock of similar depth and source mechanism. Broadband waveform comparisons of the main event and this aftershock are shown in Figure 2. The seismograms recorded at stations to the north of both events are very similar in shape and timing, though their amplitudes are different by three orders of magnitude. In contrast, the Rayleigh waves from the mainshock are considerably delayed relative to the aftershock at stations to the south (i.e., BAR). This observation motivates further investigation of rupture directivity.

Based on the above considerations, we address three issues. First, we establish faulting parameters using only the body waves. They should be less influenced by basin effects, compared to the surface waves. Second, we model complete displacement records of the 17:56 GMT aftershock (Fig. 1) and the mainshock using theoretical Green's functions. Finally, as the main purpose of this article, we examine fault dimension and rupture directivity and estimate the seismic moment of the main event, using the waveforms from the 17:56 GMT aftershock as empirical Green's functions. 


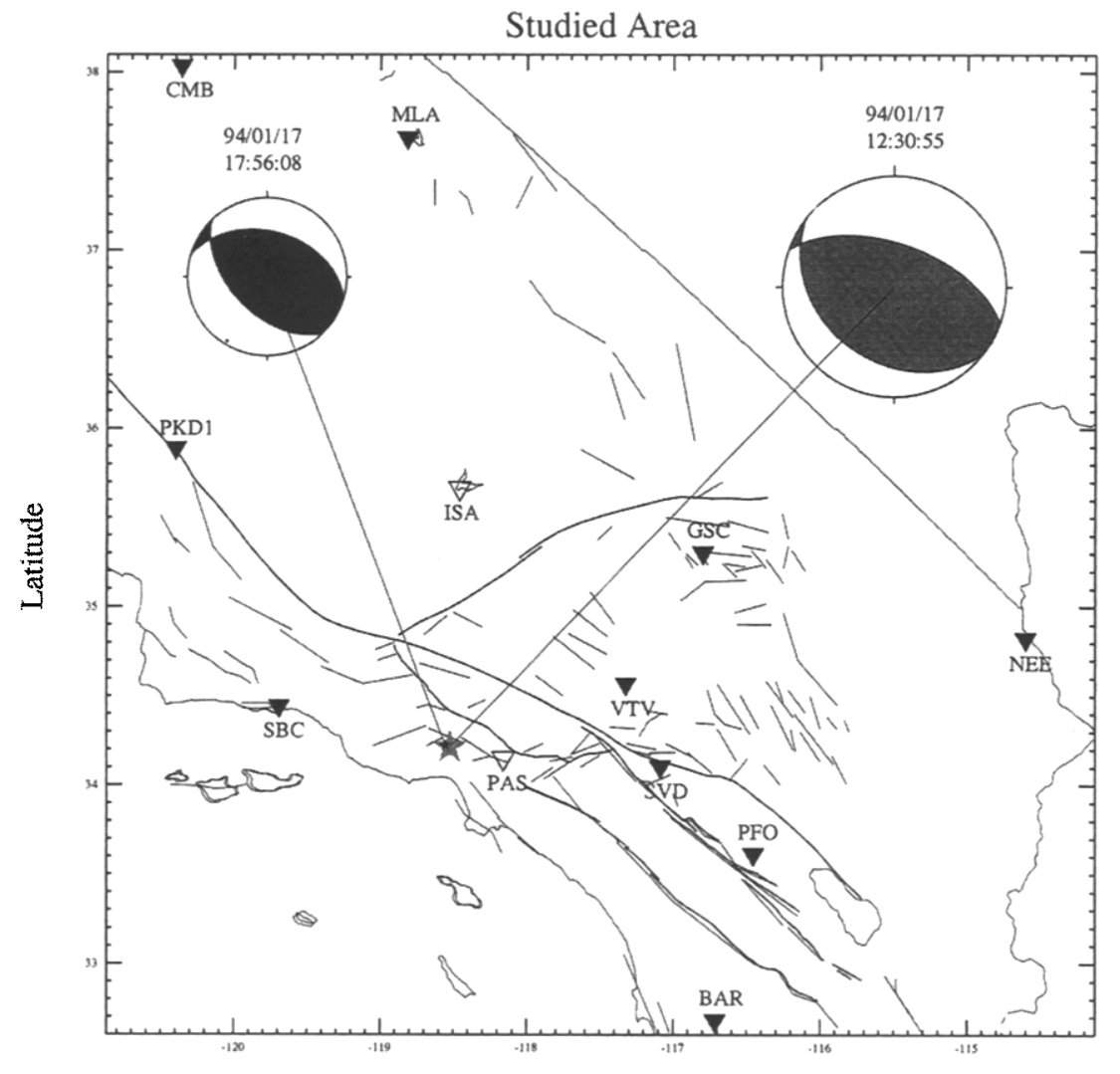

Longitude
Figure 1. Some of the broadband stations (triangles) in southern California and the epicenters of the mainshock (gray star) and the aftershock (dark star). Stations used in this study are shown with solid triangles. Also shown are the origin times and our preferred double-couple source mechanisms for the two earthquakes.

\section{Source Estimation with Theoretical Green's Functions}

We first estimate the mainshock source parameters using a grid-search source-estimation algorithm, attributed to Zhao and Helmberger (1994). This method selects the source mechanism that minimizes the L1 and L2 norms between the data and synthetics and often produces a stable solution from a relatively sparse data set. For this procedure, we use broadband displacement records from five TERRAscope stations (BAR, GSC, MLA, PFO, SBC) and two BDSN stations (CMB, PKD1) (Fig. 1). The source is modeled with a point double-couple with a trapezoidal far-field source-time function $(1.5,1.5$, and $1.5 \mathrm{sec})$. The standard southern California crustal model (SC) (Dreger and Helmberger, 1991) is used for most of the stations except station NEE, for which we use a model developed for the Basin and Range province by Song and Helmberger (1995). Synthetic seismograms are generated by a frequency-wavenumber matrix propagation algorithm (Saikia, 1994).

Source estimation is done in two steps. In the first step, only the $P_{n l}$ waves recorded at the above stations are used in the process, and we cycle through different source depths $(11,15$, and $19 \mathrm{~km})$. Estimated source parameters for different focal depths are presented in Table 1. Figure 3 compares the $P_{n l}$ portion of the broadband data and synthetics for source depths of 11 and $19 \mathrm{~km}$. The source mechanisms obtained are also shown. The fits between data and synthet- ics are generally good, with small differences between fits for each depth. The source parameters for the three depths are very similar. These are probably because the source propagation spans a substantial depth range. However, fits between the data and synthetics for a source depth of $19 \mathrm{~km}$ are better than those for a source depth of $11 \mathrm{~km}$, especially near the onset of the $P_{n l}$ waves at stations PFO and BAR (Fig. 3). This suggests that the source was deep or, at least, that the rupture began at a depth closer to $19 \mathrm{~km}$ than to $11 \mathrm{~km}$. The average depth is near $15 \mathrm{~km}$ according to the above criteria used in this estimation technique, and the fits between the $P_{n l}$ data and the corresponding synthetics for a source depth of $15 \mathrm{~km}$ appear to be the best in an average sense among the three depths tested (Figs. 3 and 4). In the second step, we fix the depth at $15 \mathrm{~km}$ and add in surface waves in the estimation procedure. Figure 4 shows the comparison between the broadband data and the corresponding synthetics for the mechanism obtained in the whole waveform source estimation. At most of the stations, the $P_{n l}$ waves and the surface waves are both modeled reasonably well. This estimation was done to see if the surface waves require the same source orientation as the $P_{n l}$ waves, since the surface waves should be more sensitive to the shallow structure. That is, if the mechanism changed dramatically during the rupture, we might expect to get a different source mechanism by including surface waves in the estimation. However, ad- 


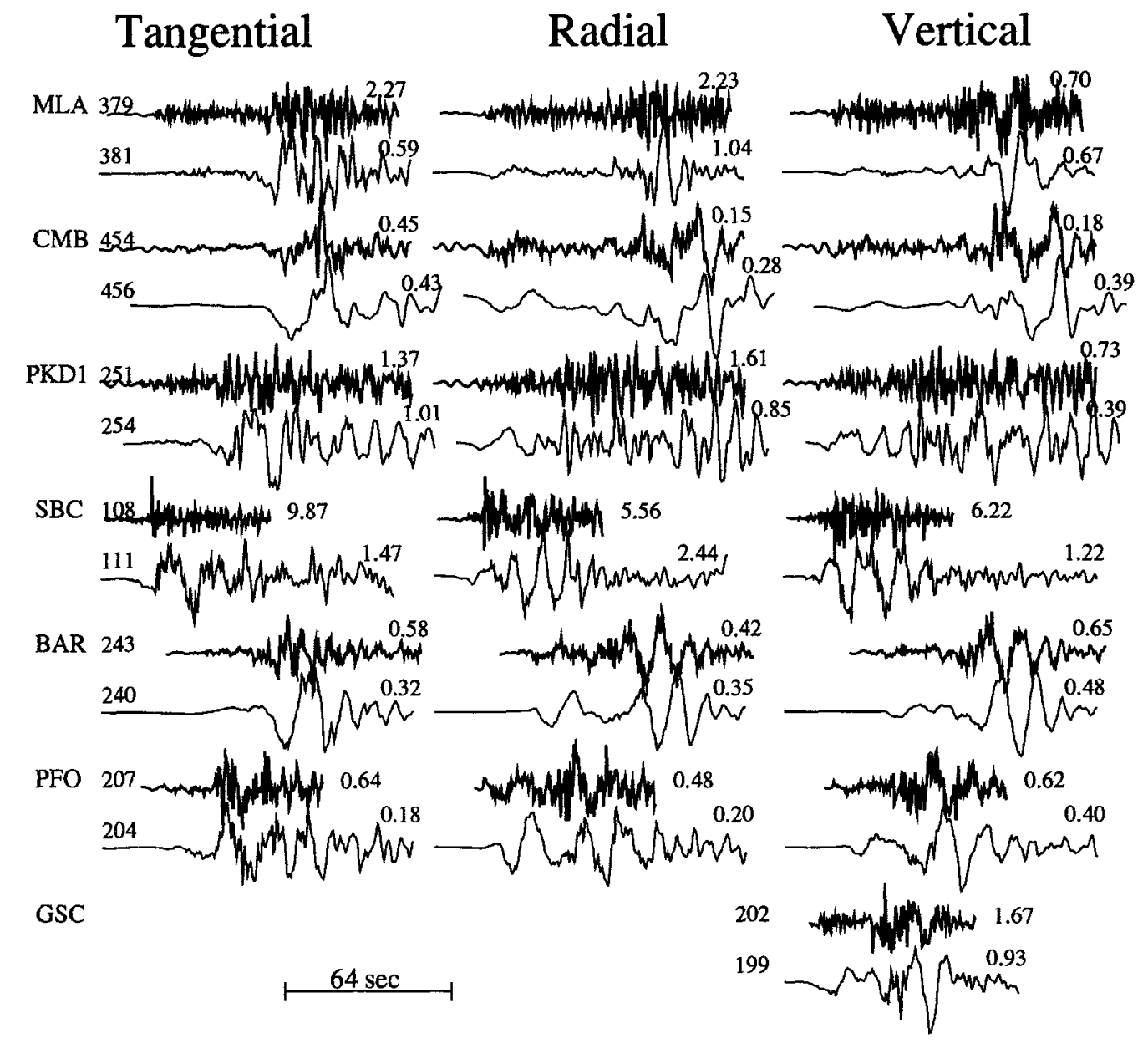

Figure 2. Comparison of the broadband displacement records between the Northridge mainshock (light traces) and the aftershock (heavy traces). Seismograms in each pair are aligned in absolute travel time. Station names, distances $(\mathrm{km})$, and peak amplitudes (cm for the mainshock and $10^{-3} \mathrm{~cm}$ for the aftershock) are also shown.

dition of the surface waves to the $P_{n l}$ waves in the procedure produces the same mechanism as that obtained with the $P_{n l}$ waves alone (Table 1). This feature makes the eGf study in the next section reasonable, since apparently only one fault plane was involved. The seismic moment obtained from the whole waveform estimation is smaller than that obtained using the $P_{n i}$ waveforms alone. This again suggests that a substantial portion of the earthquake energy was released deeper than $15 \mathrm{~km}$.

Some attention needs to be paid to the far-field sourcetime function. The $(1.5,1.5$, and $1.5 \mathrm{sec})$ trapezoid seems to work well for the $P_{n l}$ waves, as is seen in the synthetic waveforms in Figures 3 and 4. For surface waves shown in Figure 4 , however, the synthetics are shorter period than the data by a factor of 2, especially at stations BAR and PFO to the south. This is not unexpected, since the slowly traveling surface waves should see a longer source duration for a propagating source. We address the issue of source propagation in the next section, with an eGf study.

Ideally, an event used as an eGf should be at the same
Table 1

Source Parameters Estimated for the Mainshock

\begin{tabular}{cccccc}
\hline $\begin{array}{c}\text { Data } \\
\text { Used }\end{array}$ & $\begin{array}{c}\text { Focal Depth } \\
\text { Assumed }(\mathbf{k m})\end{array}$ & $\begin{array}{c}\text { Strike } \\
\left({ }^{\circ}\right)\end{array}$ & $\begin{array}{c}\text { Dip } \\
\left({ }^{\circ}\right)\end{array}$ & $\begin{array}{c}\text { Rake } \\
\left({ }^{\circ}\right)\end{array}$ & $\begin{array}{c}\text { Moment }^{*} \\
\left(10^{25} \text { dyne-cm) }\right.\end{array}$ \\
\hline$P_{n l}$ & 11 & 132 & 35 & 113 & 9.4 \\
$P_{n l}$ & 15 & 128 & 33 & 106 & 10. \\
$P_{n l}$ & 19 & 126 & 28 & 99 & 13. \\
Whole & 15 & 128 & 33 & 106 & 8.1 \\
\hline
\end{tabular}

*Our best moment estimate is $(1.4 \pm 0.9) \times 10^{26}$ dyne-cm from the eGf study.

location and have the same source mechanism as the event being investigated, to ensure that both earthquakes have similar source and propagational effects. To this end, we select the 17 January 1994 17:56 GMT aftershock as an eGf for our study. This small event occurred within $5 \mathrm{~km}$ of the mainshock, at the location $\left(118.57^{\circ} \mathrm{W}, 34.22^{\circ} \mathrm{N}\right)$ and at a depth of roughly 17 to $20 \mathrm{~km}$ (Thio and Kanamori, 1996; Hauksson et al., 1994). 


\section{Radial Pnl}

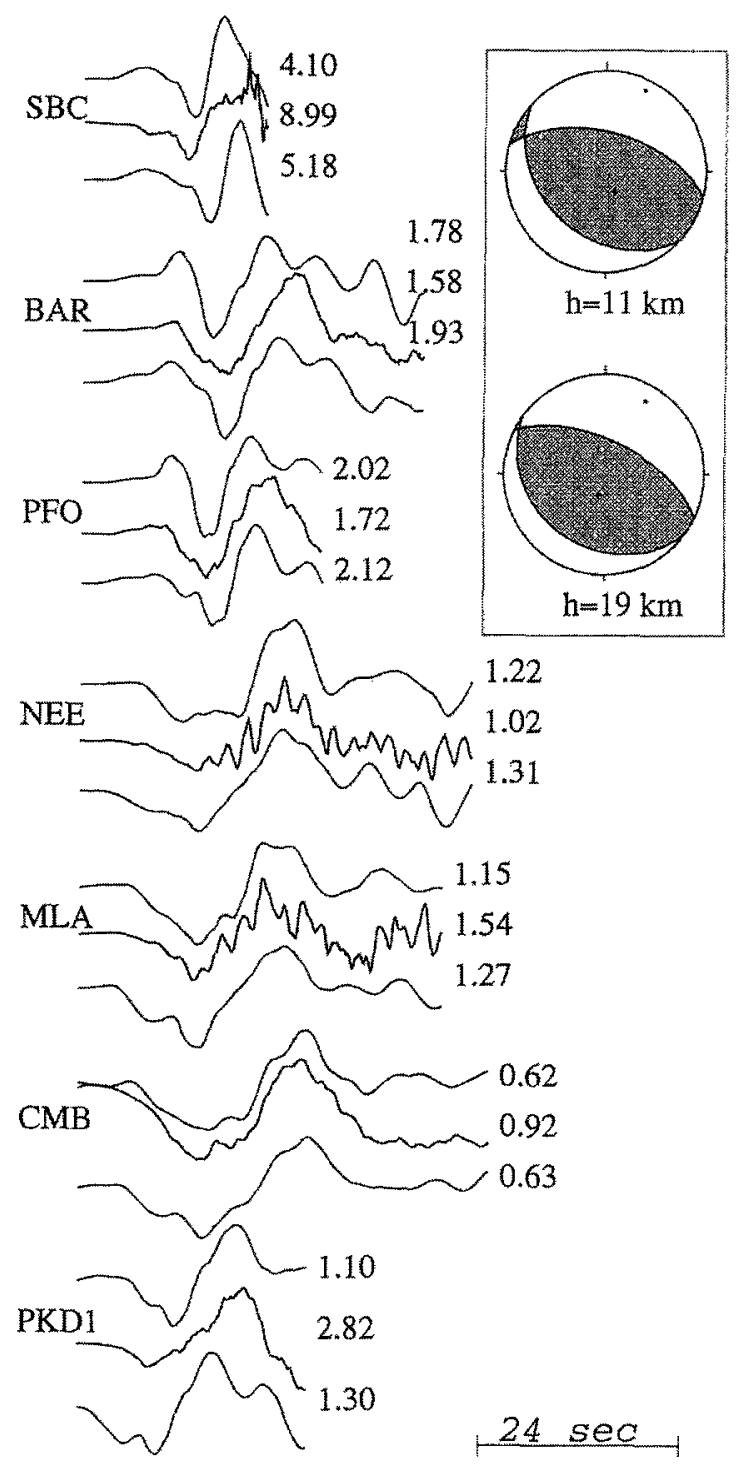

\section{Vertical Pnl}
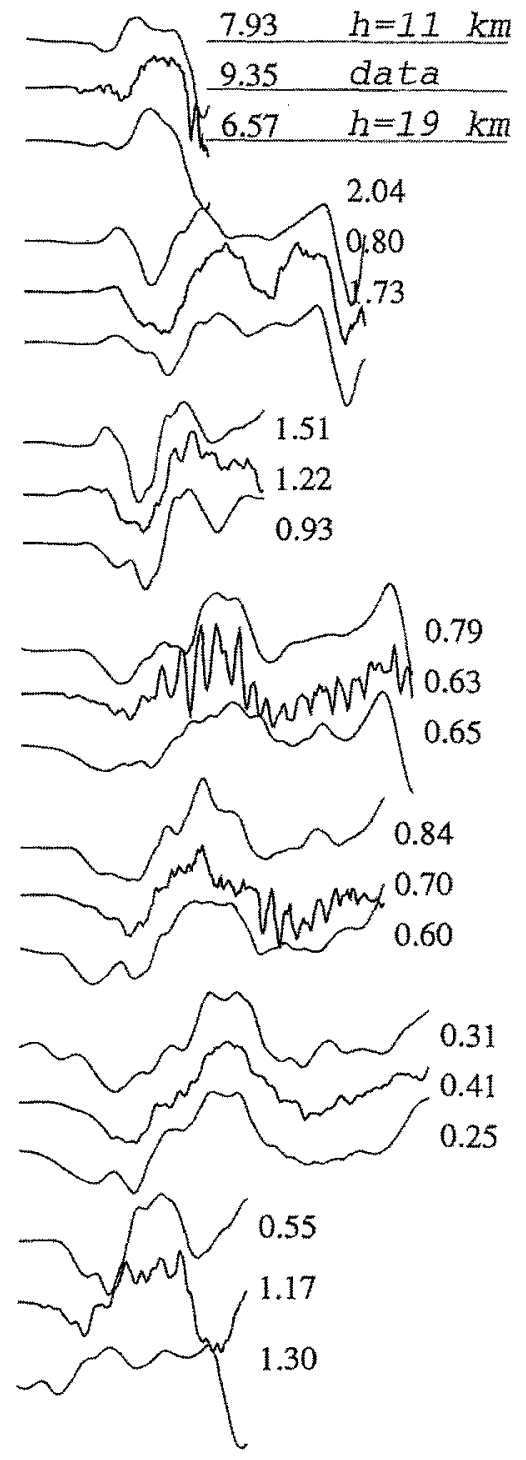

Figure 3. Comparison of broadband displacement data (mainshock, $P_{n !}$ only) and the corresponding synthetic waveforms. The middle heavy traces are data. Top traces are synthetics assuming a source depth of $11 \mathrm{~km}$, and bottom traces are synthetics for a source depth of $19 \mathrm{~km}$. Peak amplitudes $(\mathrm{mm})$ are shown above each trace, given the appropriate seismic moment (Table 1) for the synthetics. The source mechanism solutions for the two source depths are also shown.

A source mechanism was obtained for this aftershock using the same source estimation procedure and broadband records convolved with a long-period Press-Ewing (LP3090) instrument response. The convolution was necessary due to the large high-frequency component in the records, which could otherwise have been difficult to model. This also desensitizes our moment estimation to the attenuation factors in the crustal model used for the tGf's and reduces the related uncertainty. Our modeling analysis indicates that this small event has a very short source duration no broader than 0.4 sec. Source estimation at long period with different depths
$(14,17$, and $20 \mathrm{~km})$ yields about the same source mechanism. Figure 5 shows the comparison of broadband records (aftershock) convolved with a LP3090 response and appropriate synthetics for the depth of $17 \mathrm{~km}$. The source mechanism obtained for the aftershock (strike $120^{\circ}$, dip $42^{\circ}$, and rake $100^{\circ}$ ) is quite similar to that of the mainshock. The seismic moment obtained is $(6.8 \pm 2.5) \times 10^{22}$ dyne-cm. The uncertainty in the moment estimation reflects the scattering in the peak amplitude ratio between the data and the synthetic waveforms. It does not include that introduced by the uncertainty in assuming the crustal model (SC), mainly 


\section{$\begin{array}{lcccc}\text { Tangential } & \begin{array}{c}\text { Radial } \\ \text { Pnl }\end{array} & \begin{array}{c}\text { Vertical } \\ \text { Pnl }\end{array} & \text { Radial } & \text { Vertical }\end{array}$}

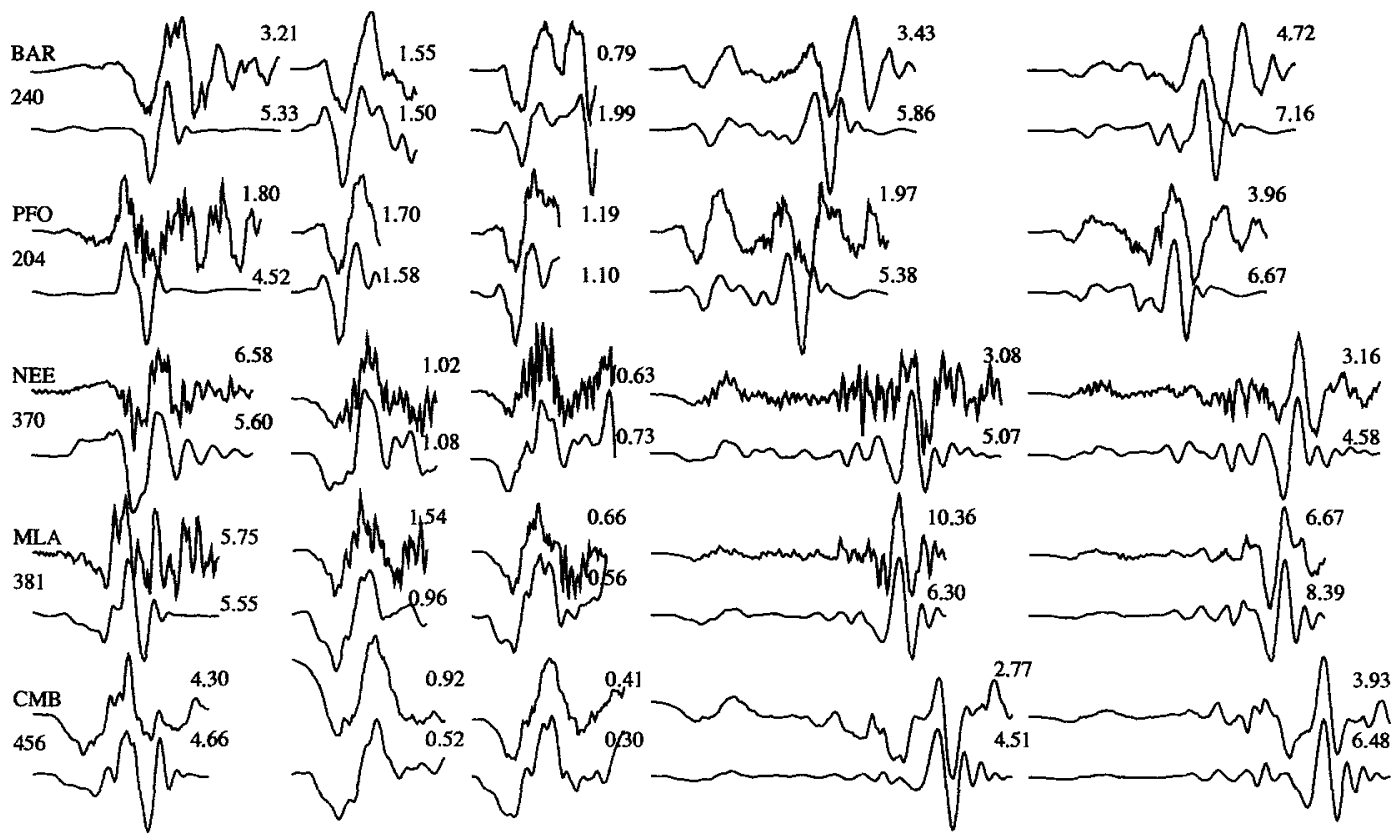

Pnl R Pnl Z

Pnl R

Pnl Z

PKD
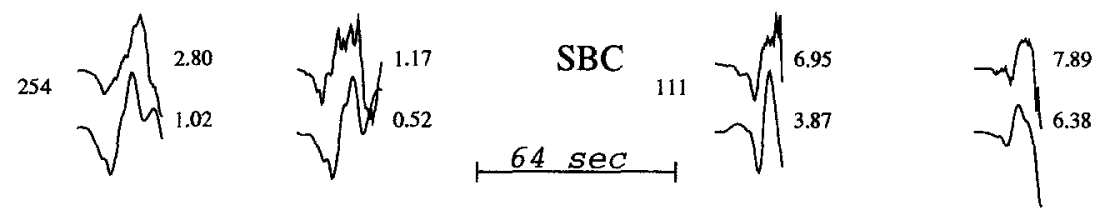

Figure 4. Comparisons of broadband displacement data (mainshock, whole waveform; top traces) and the corresponding synthetic waveforms (bottom traces), assuming a source depth of $15 \mathrm{~km}$. Source estimation with $P_{n l}$ waves only and that with the whole waveform yield about the same mechanism. Peak amplitudes $(\mathrm{mm})$ are given above each trace, given a seismic moment of $8.1 \times 10^{25}$ dyne-cm for the synthetics.

in the receiver functions at various stations, which may cause an error of up to $20 \%$ in the moment estimation. The latter is due to the fact that one could usually model the surface waves with the velocities of the surface layer varying by $20 \%$, given the appropriate velocity-thickness trade-off (e.g., Song and Helmberger, 1995). Taking this into account, we estimate the aftershock moment to be $(6.8 \pm 3.9) \times 10^{22}$ dyne-cm. We address later how the first part of the uncertainty might be reduced.

\section{Source Characteristics from eGf Modeling}

The main event is larger in moment than the aftershock by three orders of magnitude, but the waveform comparisons in Figure 2 show some similarities in wave shape. However, there are lags in absolute timing between the waveforms of the aftershock and of the main event. While time lags at stations to the north (i.e., CMB and MLA) are small, those at stations to the south (i.e., BAR and PFO) are comparatively large. These are indications of mainshock source directivity. As discussed above, the aftershock has a very short duration and a mechanism and location very similar to those of the main event. It is thus an appropriate eGf for use in a study of the mainshock source characteristics.

However, there are some assumptions that need to be explained in the present use of empirical Green's functions. We can express the displacement of the aftershock as

$$
\begin{aligned}
S_{A}(t, \mathbf{r}) & =G(t, \mathbf{r}, \boldsymbol{\xi}, \tau) * \delta\left(\tau-\tau_{a}\right) * \delta(\boldsymbol{\xi} \\
& \left.-\xi_{a}\right) *\left[M_{a} s_{a}(t)\right]=G\left(t, \mathbf{r}, \xi_{a}, \tau_{a}\right) *\left[M_{a} s_{a}(t)\right],
\end{aligned}
$$

where $G(t, \mathbf{r}, \boldsymbol{\xi}, \tau)$ is the propagational Green's function or the far-field displacement due to a point source of step dislocation with unit moment at time $\tau$ and source position vector $\boldsymbol{\xi}$. The Green's function has a dimension of length/energy. $s_{a}(t)$ is the far-field source-time function of the aftershock. It is normalized to unit area and has a dimension of $1 /$ time. $M_{a}$ is the seismic moment of the aftershock. 


\section{$\begin{array}{lllll}\text { Tangential } & \substack{\text { Radial } \\ \text { Pnl }} & \substack{\text { Vertical } \\ \text { Pnl }} & \text { Radial } & \text { Vertical }\end{array}$}
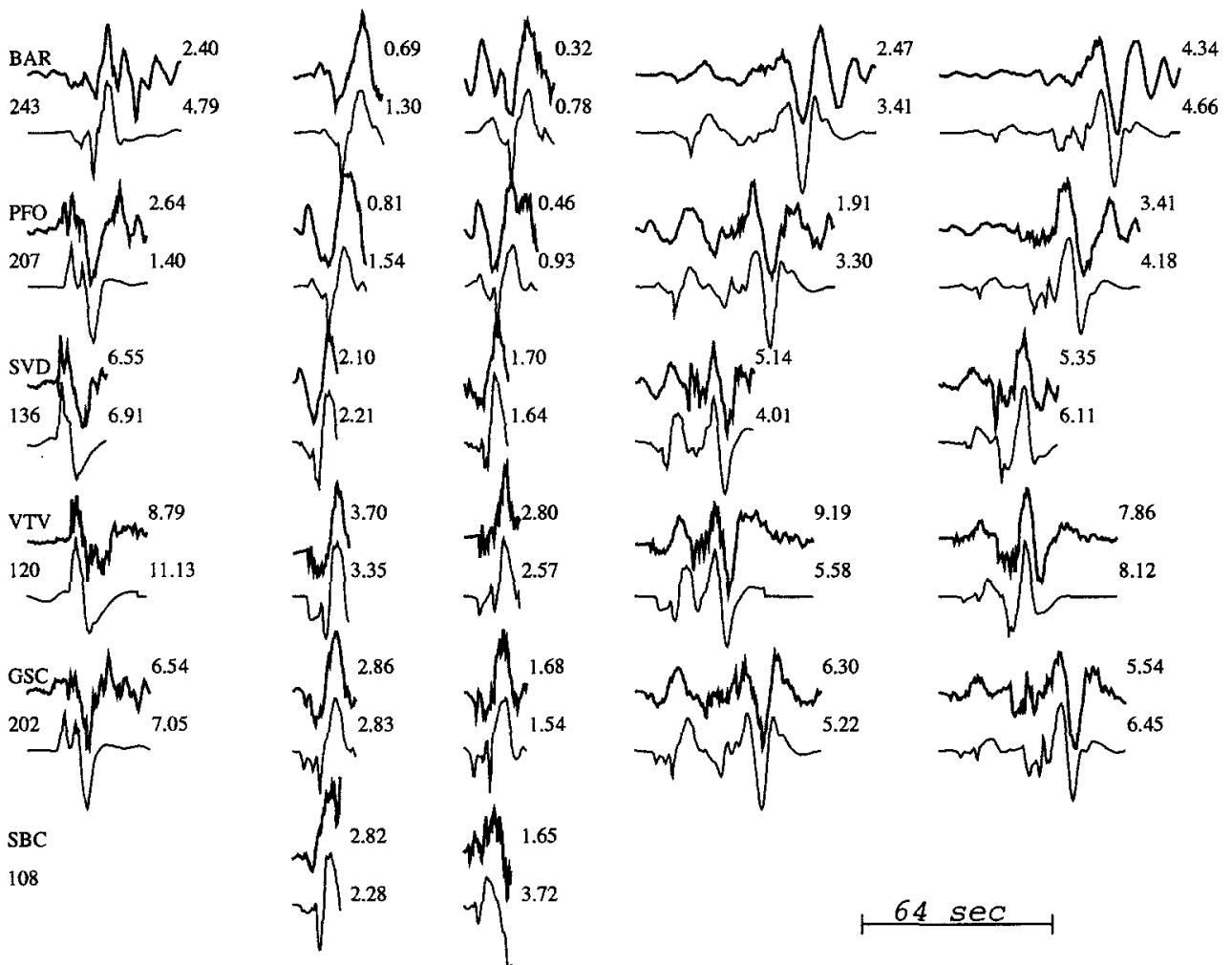

Figure 5. Comparisons of broadband displacement data (top traces), convolved with a long-period Press-Ewing instrument response, and the corresponding synthetic waveforms (bottom traces) for the aftershock, assuming a source depth of $17 \mathrm{~km}$. Peak amplitudes. $\left(10^{-3} \mathrm{~mm}\right)$ are given above each trace, given a moment $M_{0}=6.8 \times 10^{22}$ dyne-cm for the synthetics.

Suppose the main event is represented by a cluster of point sources of step dislocation in the source region, each with a moment $m(\xi) d A$, where $d A$ is the infinitesimal area. The displacement produced by each point source, $\left(\boldsymbol{\xi}_{s}, \tau_{s}\right)$, is

$$
S_{s}(t, \mathbf{r})=G\left(t, \mathbf{r}, \boldsymbol{\xi}_{s}, \tau_{s}\right) *\left[m\left(\boldsymbol{\xi}_{s}\right) d A \delta(t)\right]
$$

Note that $\tau_{s}$ is related to $\boldsymbol{\xi}_{s}$ through the rupture velocity vector. Using the reciprocal relation for source and receiver times (Aki and Richards, 1980), we can rewrite $S_{s}(t, \mathbf{r})$ as

$$
S_{s}(t, \mathbf{r})=G\left(t, \mathbf{r}, \boldsymbol{\xi}_{s}, \tau_{a}\right) *\left\{m\left(\boldsymbol{\xi}_{s}\right) d A \delta\left[t-\Delta t\left(\boldsymbol{\xi}_{s}\right)\right]\right\}
$$

where $\Delta t\left(\boldsymbol{\xi}_{s}\right)=\left(\tau_{s}-\tau_{a}\right)$ is a function of $\boldsymbol{\xi}_{s}$.

The main event displacement is the sum of displacement of all the point sources:

$$
\begin{aligned}
& S_{M}(t, \mathbf{r})=\int_{A} \int S_{s}(t, \mathbf{r}) \\
& =\int_{A} \int G\left(t, \mathbf{r}, \boldsymbol{\xi}_{s}, \tau_{a}\right) *\left\{m\left(\boldsymbol{\xi}_{s}\right) \delta\left[t-\Delta t\left(\boldsymbol{\xi}_{s}\right)\right]\right\} d A .
\end{aligned}
$$

For small enough source dimension, we can assume

$$
\begin{aligned}
G\left(t, \mathbf{r}, \boldsymbol{\xi}_{s}, \tau_{a}\right)=F\left(\boldsymbol{\xi}_{s}-\boldsymbol{\xi}_{a}\right) G\left(t, \mathbf{r}, \boldsymbol{\xi}_{a}, \tau_{a}\right) * \delta[t \\
\\
\left.-\Delta t^{\prime}\left(\boldsymbol{\xi}_{s}-\boldsymbol{\xi}_{a}, \mathbf{r}\right)\right] .
\end{aligned}
$$

That is, the difference in the Green's function due to the spatial separation between a point source of the main event and the aftershock can be represented by a time delay $\Delta t^{\prime}\left(\boldsymbol{\xi}_{s}\right.$ $\left.-\boldsymbol{\xi}_{a}, \mathbf{r}\right)$ and a scale factor $F\left(\boldsymbol{\xi}_{s}-\boldsymbol{\xi}_{a}\right)$. Note, however, that this approximation would be more appropriate if we use a particular correction for each arrival based on its phase velocity. Fortunately, it is the surface waves that dominate the records, which have predictable phase velocities. Moreover, surface waves are relatively long period and their waveforms are less affected by small source mislocation. Thus, this assumption is justified for surface waves. The scale factor $F\left(\boldsymbol{\xi}_{s}\right.$ $-\boldsymbol{\xi}_{a}$ ) is due to the difference in source depth between the point source of the main event and the aftershock and should be determined by the amplitude ratio of their surface waves. For simplicity, we can approximate $F\left(\boldsymbol{\xi}_{s}-\boldsymbol{\xi}_{a}\right)$ by its value at the center of the rupture segment, $F\left(\boldsymbol{\xi}_{c}-\boldsymbol{\xi}_{a}\right)$.

Since $G\left(t, \mathbf{r}, \boldsymbol{\xi}_{a}, \tau_{a}\right)$ is independent of $\boldsymbol{\xi}_{s}$, we are now able to rewrite equation (4) by convolving both sides with $s_{a}(t)$. (Recall that $s_{a}(t)$ is the far-field source-time function of the aftershock.) 


$$
\begin{gathered}
S_{M}(t, \mathbf{r}) * s_{a}(t) \\
=G\left(t, \mathbf{r}, \boldsymbol{\xi}_{a}, \tau_{a}\right) *\left[M_{a} s_{a}(t)\right] * \frac{F\left(\boldsymbol{\xi}_{c}-\boldsymbol{\xi}_{a}\right)}{M_{a}} \cdot \int_{A} \int \delta[t \\
\left.-\Delta t^{\prime}\left(\boldsymbol{\xi}_{s}-\boldsymbol{\xi}_{a}, \mathbf{r}\right)\right]^{*}\left\{m\left(\boldsymbol{\xi}_{s}\right) \delta\left[t-\Delta t\left(\boldsymbol{\xi}_{s}-\boldsymbol{\xi}_{a}\right)\right]\right\} d A .
\end{gathered}
$$

Using equation (1), we have

$$
\begin{array}{r}
S_{M}(t, \mathbf{r}) * s_{a}(t)=\frac{F\left(\boldsymbol{\xi}_{c}-\boldsymbol{\xi}_{a}\right) S_{A}(t, \mathbf{r})}{M_{a}} * \int_{A} \int m\left(\boldsymbol{\xi}_{s}\right) \delta[t \\
\left.-\Delta t^{\prime \prime}\left(\boldsymbol{\xi}_{s}-\boldsymbol{\xi}_{a}, \mathbf{r}\right)\right] d A,
\end{array}
$$

where $\Delta t^{\prime \prime}\left(\boldsymbol{\xi}_{s}-\boldsymbol{\xi}_{a}, \mathbf{r}\right)=\Delta t^{\prime}\left(\boldsymbol{\xi}_{s}-\boldsymbol{\xi}_{a}, \mathbf{r}\right)+\Delta t\left(\boldsymbol{\xi}_{s}\right)$. Assuming $s_{a}(t)=\delta(t)$, or the aftershock is small enough, this expression can be written as

$$
S_{M}(t, \mathbf{r})=\left(F\left(\boldsymbol{\xi}_{c}-\xi_{a}\right) \frac{M_{m}}{M_{a}}\right) S_{A}(t, \mathbf{r}) * s_{m}(t, \mathbf{r})
$$

with $M_{m}$ being the seismic moment of the main event and $s_{m}(t, \mathbf{r})$ its far-field source-time function at a particular station.

$$
S_{m}(t, \mathbf{r})=\frac{1}{M_{m}} \int_{A} \int m\left(\boldsymbol{\xi}_{s}\right) \delta\left[t-\Delta t^{\prime \prime}\left(\boldsymbol{\xi}_{s}-\boldsymbol{\xi}_{a}, \mathbf{r}\right)\right] d A
$$

If we further assume uniform rupture, $m\left(\boldsymbol{\xi}_{s}\right)=M_{m} / A$, we obtain

$$
S_{m}(t, \mathbf{r})=\frac{1}{A} \int_{A} \int \delta\left[t-\Delta t^{\prime \prime}\left(\boldsymbol{\xi}_{s}-\boldsymbol{\xi}_{a}, \mathbf{r}\right)\right] d A
$$

This expression reduces to a unit-area trapezoidal function if we simulate the rupture with a line of point sources sweeping through a rectangular fault plane (Fig. 6), as demonstrated by Langston (1978). Parameters of the trapezoid for a certain station depend on the fault dimension and the rupture velocity and direction or just two parameters, the fault dimension and the rupture direction, assuming a square fault and a rupture velocity.

To obtain the appropriate trapezoids for each station, we search through a set of unit-area trapezoids and convolve the aftershock data with each tested trapezoidal function to simulate the mainshock data for each component. We then compare the simulations with the data to select the most appropriate trapezoid for that component. A criterion based on the averaged L1 and L2 norm (Zhao and Helmberger, 1994) is used for this purpose. Figure 7 shows comparison between the mainshock displacement data and results from the convolution. At most of the stations (i.e., MLA, CMB, BAR, and GSC vertical), the empirical simulations fit the mainshock data very well, with especially good fits to the Rayleigh waves. However, some of the Love-wave com-

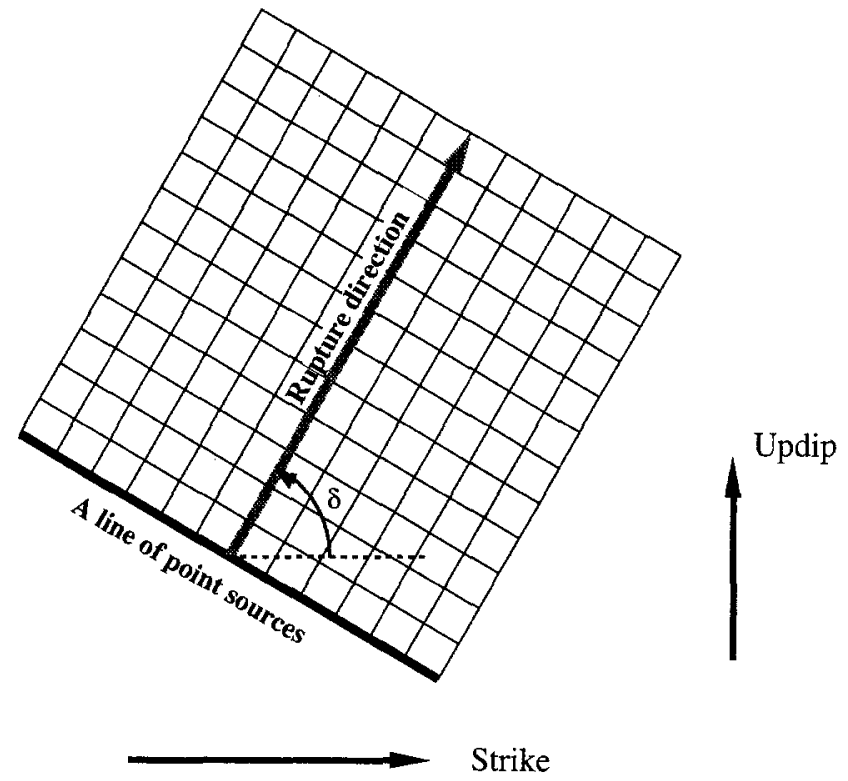

Figure 6. Map view of a discretized fault. Rupture is simulated by a line of point sources sweeping through a rectangular fault segment in the direction normal to the line itself. The rupture angle $\delta$ is defined here to specify the rupture direction.

plexity at short periods is not as well modeled, most notably at stations SBC and PFO, which will be discussed later.

The duration of the trapezoids required for the best simulation (Fig. 7) varies azimuthally from station to station, with narrow trapezoids required for stations to the north and broader trapezoids required for stations to the south. To explain this azimuthal variation, we average the trapezoid duration for three components at each station and model the duration as a function of azimuth with Langston's formulation. In this procedure, we assumed rupture on a square fault with a rupture velocity of $3 \mathrm{~km} / \mathrm{sec}$. We also assumed a Rayleigh-wave velocity of $3 \mathrm{~km} / \mathrm{sec}$ and a Love-wave velocity of $3.1 \mathrm{~km} / \mathrm{sec}$, as obtained from the surface-wave synthetics (SC model). With these, we obtained a fault dimension of $14 \mathrm{~km}$. Figure 8 shows the comparison between the observed trapezoid duration and the calculated duration for rupture in three different directions on a square fault of the above dimension. Among these predictions, $\delta=106^{\circ}$ gives the best fit to the azimuthal variation of the source duration, indicating rupture along the direction of the average rake vector.

Figure 9a displays the eGf simulation to the mainshock data using the predicted trapezoids for each station by the uniform rupture model with $\delta=106^{\circ}$. The agreement with the observed waveforms is about as good as in Figure 7. This result suggests that the fault dimension and the rupture direction are the most important variables and can be easily estimated following the above procedure. Such a procedure might be automated and used in routine processing of broadband array data. 


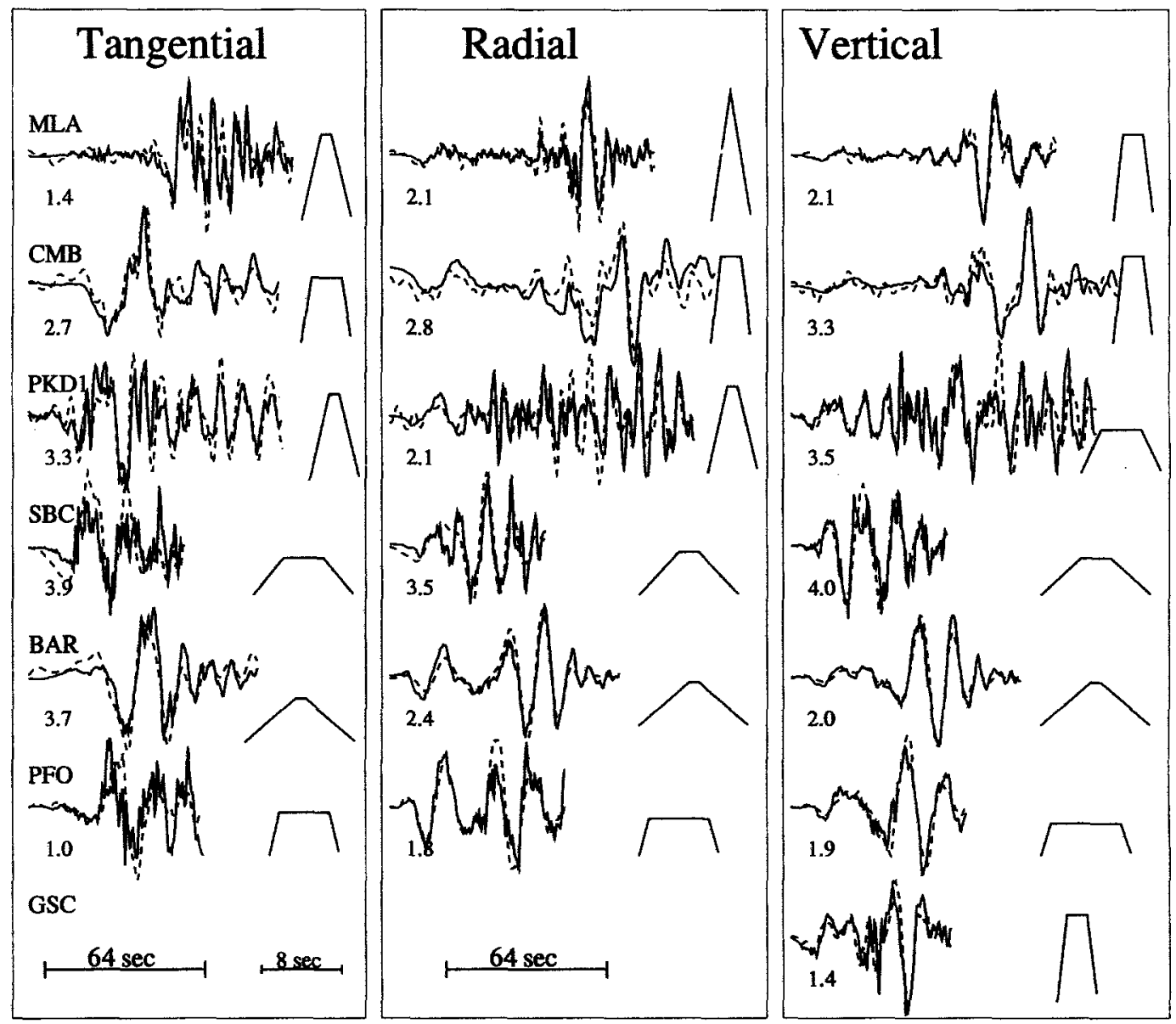

Figure 7. Comparison of displacement data (solid traces) from the Northridge mainshock and the corresponding empirical simulations (dashed traces). Each pair of seismograms are aligned in absolute travel time. Also plotted are the trapezoidal far-field source-time functions used for each station, as determined by our method. The small number (in thousands) indicates, for each component, the amplitude ratio of the mainshock data to the simulation.

Better fits to the observed far-field source-time functions can be obtained by allowing more parameters, as demonstrated for this same event by Dreger (1994). He achieved this by applying a deconvolution of the aftershock from the mainshock observations and inverting for individual slip vectors on a 1160-element grid. Several zones of strong slip (asperities) were identified from his procedure that presumably are controlled by the short-period signals at some stations, such as observed at SBC in Figure 9a. The reliability of these detailed results depends on the quality of the eGf's. However, nonuniform slip for this event is also recoverable from teleseismic observations, as given by Thio and Kanamori (1996). Figure 9b compares the mainshock data with the eGf simulations, using their source model. The complexity in this source model does improve the short-period empirical fitting to the mainshock data at some stations. For example, the three pulses on the tangential component at station SBC are modeled quite successfully. Although there are no significant improvements of the overall fit to the main- shock data in Figure 9b over that in Figure 9a, we do see that the regional broadband recordings bear information on the source asperity.

The average surface-wave amplitude ratio for a source at a depth of $15 \mathrm{~km}$ to one at a depth of $17 \mathrm{~km}$ is about 1.2 for the ranges studied, assuming the $\mathrm{SC}$ structure. Choosing this value for $F\left(\boldsymbol{\xi}_{c}-\boldsymbol{\xi}_{a}\right)$ in equation (8), we obtain a moment of $(1.5 \pm 1.5) \times 10^{26}$ dyne-cm for the main event from the aftershock moment (Fig. 7). The uncertainty includes those inherited from the aftershock moment estimation and those that reflect the scattering in the peak amplitude ratio between the mainshock data and the empirical simulations (Fig. 7). The latter is partially introduced by the difference between the source mechanism of the two events and the fact that the main event spanned a large depth range. We have excluded the tangential component at the station PFO in the above estimation since its peak amplitude is especially sensitive to the source mechanism change (Fig. 10), probably because it is near the null axis of the focal sphere. 


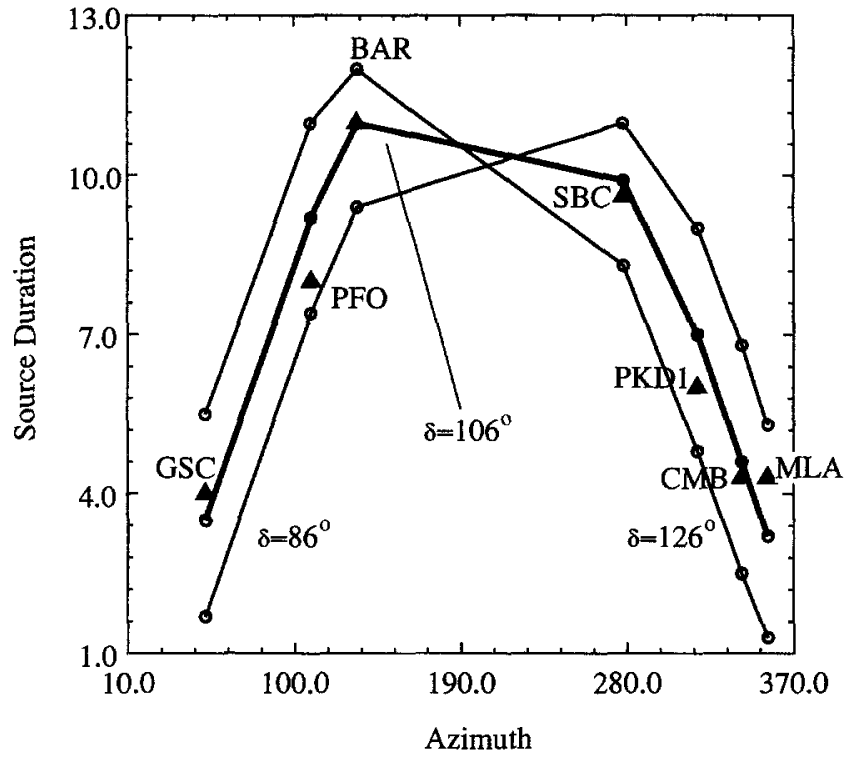

Figure 8. Comparison of the observed trapezoid width (triangles) for each station and the predicted width (circles) with $\delta=86^{\circ}, 106^{\circ}$, and $126^{\circ}$.

\section{Discussion}

To answer the question of directivity in a more elegant manner, it is necessary to explain in greater detail a few assumptions made in the preceding sections. In the process of determining the rupture direction of the main event, we have used the south-dipping plane as the fault plane. On this plane, the preferred rupture direction is parallel to the direction of the average rake vector, that is, upward and roughly northward. The main event spanned a depth range from $\sim 19$ to $12 \mathrm{~km}$. If the rupture takes place on the conjugate nodal plane, a rupture direction toward the north and downward produces equally good fits to the trapezoidal duration. Thus, just as first-motion study alone does not discern the true fault plane from its auxiliary plane, our method alone does not discern the most likely rupture direction from the other equally good candidate. However, in the case of the Northridge earthquake, we can combine the information we get in the last two sections to uniquely determine the fault plane and the rupture direction. As discussed earlier, the earthquake initiated deep, and a substantial amount of energy was released at a depth greater than the average depth. This is not inconsistent with the focal depth, $19 \mathrm{~km}$, given by Hauksson et al. (1994). However, our average source depth, in terms of energy release, is shallower than the depth of initial rupture. Thus, these arguments together suggest that rupture propagated upward and thus on the south-dipping plane, as demonstrated by the aftershock distribution (Hauksson et al., 1994). The point here is that we have developed the capability to determine this feature before the aftershock distribution information becomes available.

For an eGf study to be justified, it is required that the mainshock have the same source mechanism as the after-

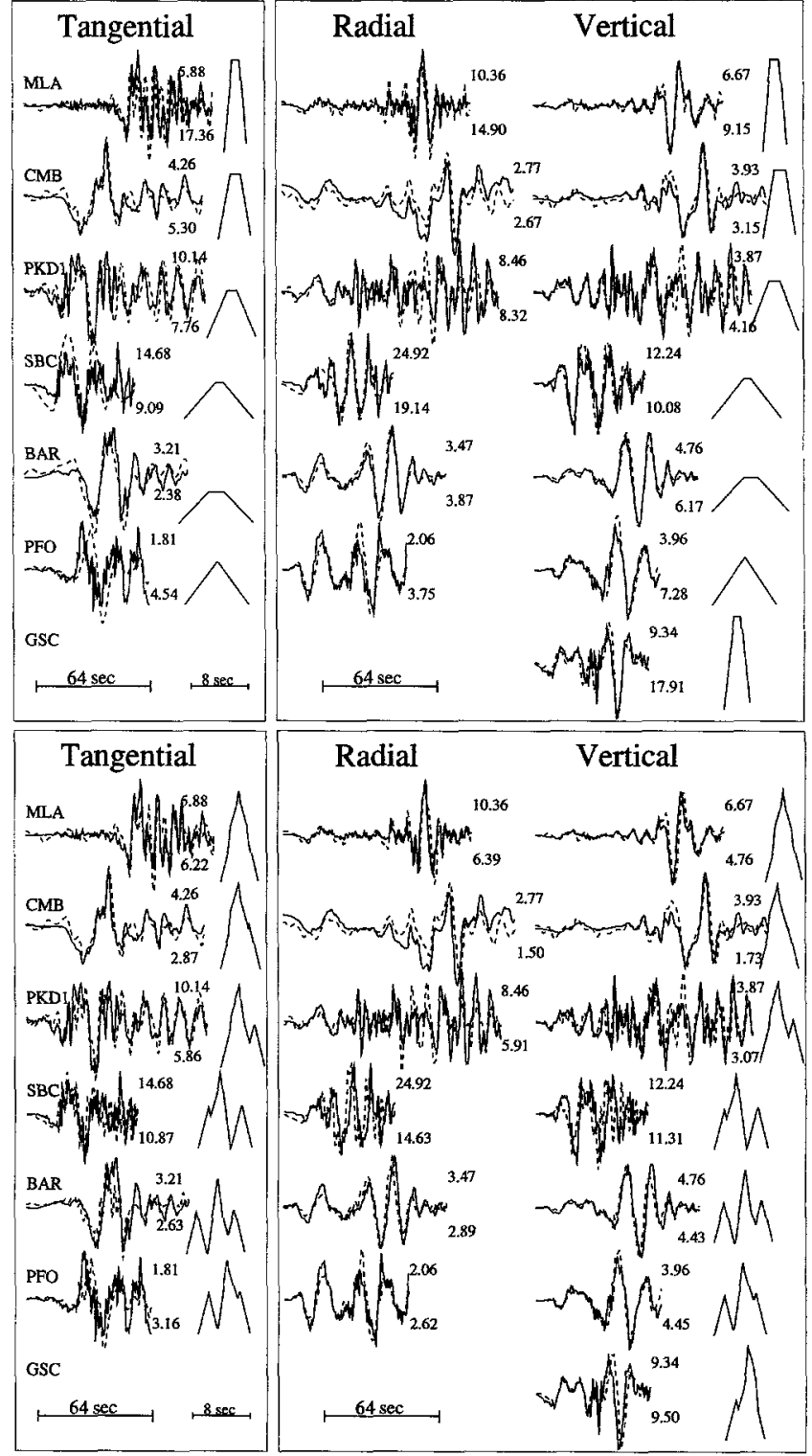

Figure 9. (a) Comparison similar to Figure 7, except that the trapezoidal far-field source-time functions used here are the predicted ones from our simple rupture model. Peak amplitudes (mm) are shown above each trace for the data and below for the simulation. An amplitude ratio of 2600 between the main event and the eGf simulation is applied. (b) Comparison similar to Figure 7, except that the moment and the far-field source-time functions used here are synthesized from the results of Thio and Kanamori (1996).

shock and that this mechanism persist during its rupture so that the radiation patterns of the two sources are similar. It is also required that the aftershock occur sufficiently close to the mainshock so that path effects and timing can be considered identical. In the Northridge earthquake study, the two events have source mechanisms similar enough that the 
Tangential

Radial

Vertical

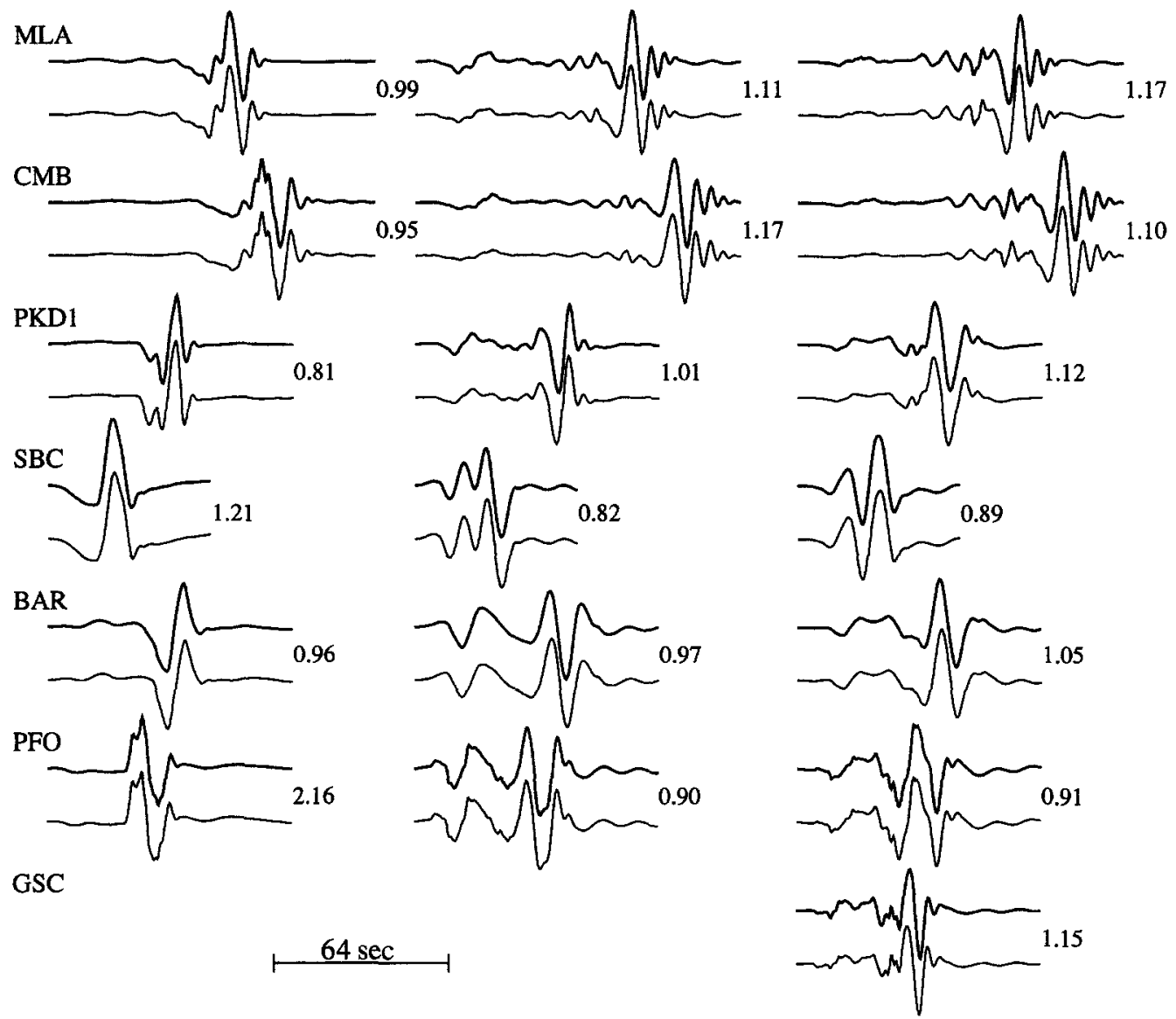

Figure 10. Comparison of two groups of synthetic waveforms generated with the aftershock source mechanism (top traces) and the mainshock source mechanism (bottom traces). A common seismic moment and the same set of far-field source-time functions in Figure 7 are used for the synthetics in each group. The number indicates the peak amplitude ratio between the bottom trace and the top trace for each pair of synthetics.

change in the synthetic waveforms due to the slight difference in the source mechanism can be ignored for our purposes (Fig. 10). Moreover, as discussed earlier, the main event remained about the same source mechanism throughout its rupture. Thus, we believe that the radiation pattern of the main event is adequately accounted for by the aftershock. Generally, if the two events are close enough to make the eGf method appropriate but are off in location by a small amount, we may see a small relative time shift between the mainshock data and the corresponding empirical simulation. In Figure 7, however, the data and the empirical simulation are aligned in absolute travel time, and no significant time shifts are observed. This indicates the compatibility of the relative location and the origin time of these two events. Note that the small uncertainty in the source depth of the aftershock has little effect on the relative timing of the regional seismograms from the two events and will not affect our conclusion of the general rupture direction. Moreover, since we have corrected for the depth effect in our moment estimation for the main event from the aftershock, the impact of the aftershock depth on the moment estimation of the main event will be small.

In Figure 11, we use broader far-field source-time functions and let them vary from station to station. Most of the misfit of the surface wave width between data and synthetics in Figure 4 disappears (e.g., stations BAR and PFO). However, the surface waves at most stations, such as PKD1 and SBC, are still not well modeled, due to the inadequacy of the tGf's. At these stations, the data contain many signals not seen on the synthetic waveforms. Some records, such as those at the station PKD1, are so complicated that it becomes difficult to distinguish body waves from surface waves. The amplitude data in Figure 5 are also scattered, which is responsible for the error in the moment estimation for the aftershock. In this figure, while the synthetic amplitude fits to the vertical (whole) are very good, with the largest error being only $23 \%$, the differences on the radial are sizeable. The amplitude ratio of radial to vertical is less than 1 for 


\section{$\begin{array}{llll}\text { Tangential } & \text { Radial } & \text { Vertical } & R / V\end{array}$}

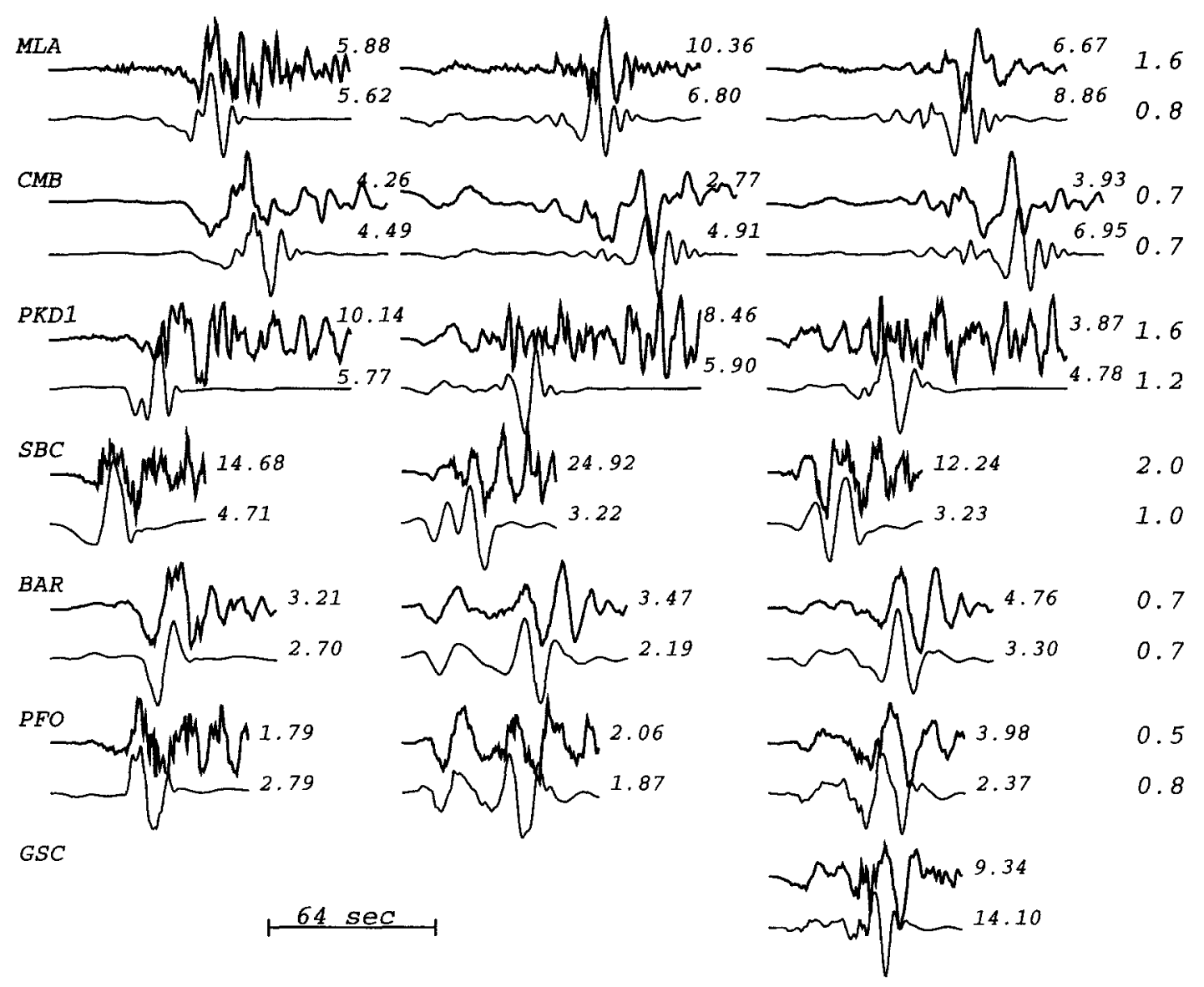

Figure 11. Comparison of displacement data (top traces) from the Northridge mainshock and the corresponding theoretical synthetics (bottom traces). Each pair of seismograms are aligned in absolute travel time. Peak amplitudes $(\mathrm{mm})$ are given above each trace. A moment of $8.1 \times 10^{25}$ dyne-cm and the same set of far-field source-time functions in Figure 7 are used for the synthetics. The rightmost column is the amplitude ratio (R/V) of the radial component to the vertical component for the data and the synthetics.

most of the synthetics, which is also true for the data at the hard-rock sites BAR and PFO. This feature is also apparent in Figure 11 in the comparison between the mainshock data and the theoretical synthetics. The stations showing the largest radial-to-vertical amplitude ratios are PKD1, SBC, and MLA. These same stations are rich in high-frequency arrivals relative to hard-rock stations (e.g., compare MLA to CMB).

Such complexities are difficult to model theoretically, but some of these features can be seen in 2D synthetics, such as those shown in Figure 12 (Stead, 1990). The upper panel of this figure shows four different crustal models (Table 2); the lower panel shows three-component seismograms corresponding to these models. Note that the waveforms, especially the $P_{n l}$ portion, are similar in all cases. This partially explains the adequacy of simple flat-layered models in obtaining source parameters with $P_{n l}$ waves alone. One substantial effect of the basin structure is the different time delays of the surface waves relative to the $P_{n l}$ waves. Compared to those in Figure 12a, Rayleigh waves in Figure 12b de- velop an extra later pulse due to the basin structure near the source region. As discussed in Ho-Liu and Helmberger (1989), this later pulse becomes more obvious when the earthquake ruptures shallow soft materials. This may have happened in the case of the Northridge earthquake, which occurred in the San Fernando Basin. Seismograms in Figure $12 \mathrm{c}$ show the same feature as those in Figure 12b. Notice the change of the tangential and radial amplitudes versus the vertical amplitude from Figures $12 \mathrm{a}$ to $12 \mathrm{~b}$ to $12 \mathrm{c}$, as slow structure begins to dominate and as the transitional structure changes. The extreme case is shown in Figure 12d. When basin structures are involved in the whole source-receiver path, the radial component of the Rayleigh wave becomes exaggerated, and the late-arriving scattered surface waves, become well developed. Paths connecting the Northridge earthquake to stations PKD1 and SBC would be two examples of these extremely complicated basin effects. Detailed $2 \mathrm{D}$ modeling along these paths would explain both the waveforms and the amplitudes much better. 


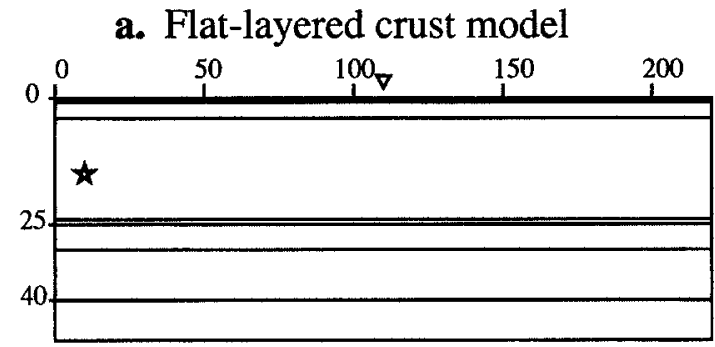

c. Gradual boundary basin model

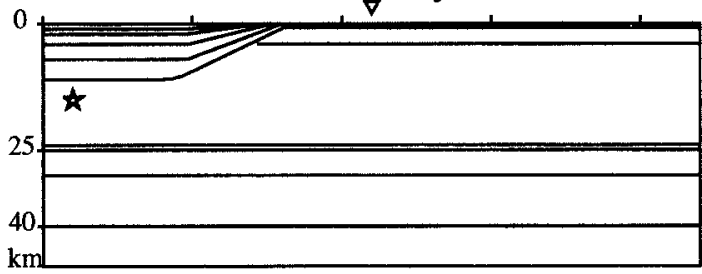

\section{b. Steep-walled basin model}

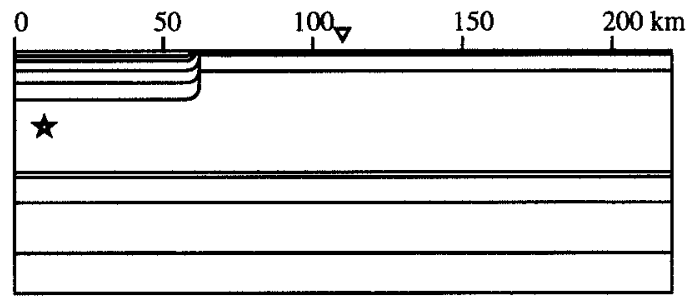

d. Flat-layered basin model

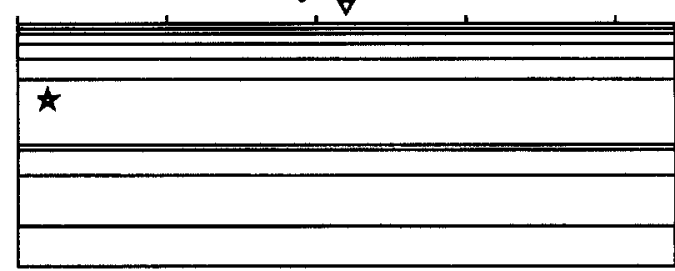

TANGENTIAL

a.

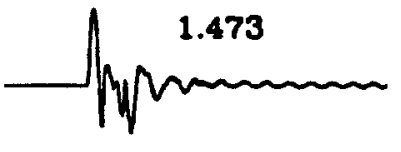

b.

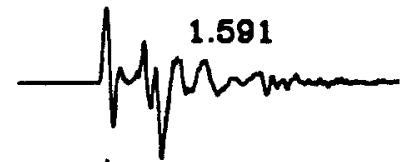

c.

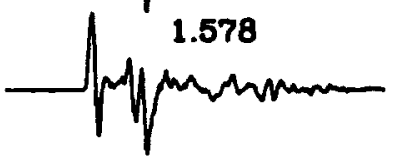

d.

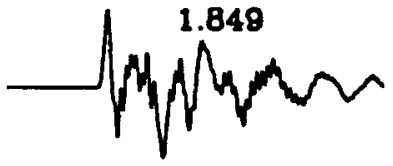

VERTICAL

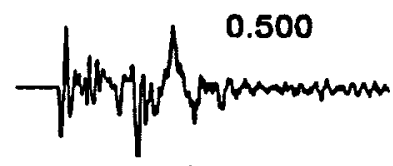

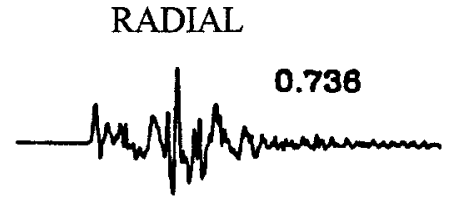
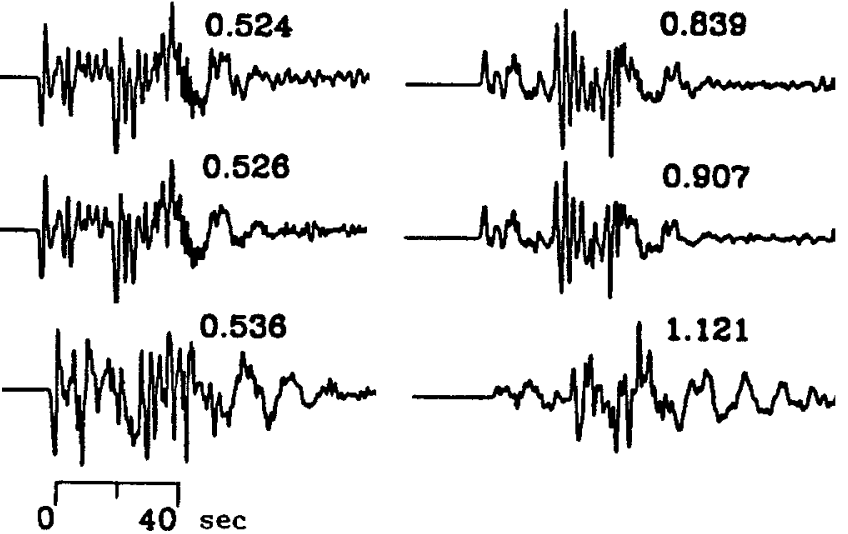
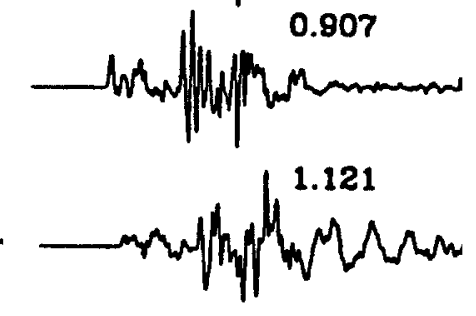

0.526

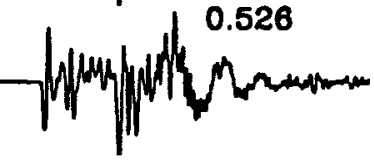

Figure 12. Four crustal models (upper panel) and corresponding three-component seismograms (lower panel) computed with a finite-difference method, after Stead (1990). Sources are indicated by stars and receivers, by triangles.

As far as the moment estimation is concerned, however, if we weight the vertical components relative to the horizontal in our moment estimation for the aftershock using the tGf approach, we would be able to reduce the moment uncertainty introduced by $2 \mathrm{D}$ effects. Thus, the seismic moment estimate for the aftershock becomes $(6.1 \pm 1.6) \times$ $10^{22}$ dyne-cm, where the error $\left(20 \%\right.$ or $\pm 1.2 \times 10^{22}$ dyne$\mathrm{cm}$ in this case) introduced by assuming a specific 1D model is the major part of the uncertainty. The mainshock moment is now estimated to be $(1.4 \pm 0.9) \times 10^{26}$ dyne-cm, where the uncertainty is larger than commonly recognized. If we take the $t \mathrm{Gf}$ approach for the mainshock moment estimation, the uncertainty would be even larger.

\section{Conclusions}

In conclusion, we estimated the source parameters of the Northridge mainshock with comparatively stable $P_{n l}$ waveforms, assuming a point double-couple source, and obtained the following solution for this earthquake: strike $128^{\circ}$, dip $33^{\circ}$, and rake $106^{\circ}$. Addition of surface waves to the estimation procedure yielded a solution consistent with that obtained from the $P_{n l}$ waveforms alone. A new method of using empirical Green's functions to constrain the fault dimension and rupture direction is introduced. Results for the Northridge earthquake suggest that the mainshock ruptured a south-dipping plane with a fault dimension of $14 \mathrm{~km}$ and 
Table 2

Elastic Constants for Models in Figure 12

\begin{tabular}{lllc}
\hline \multicolumn{1}{c}{$\begin{array}{c}V_{P} \\
(\mathrm{~km} / \mathrm{sec})\end{array}$} & $\begin{array}{c}V_{s} \\
(\mathrm{~km} / \mathrm{sec})\end{array}$ & $\begin{array}{c}\rho \\
\left(\mathrm{g} / \mathrm{cm}^{3}\right)\end{array}$ & $\begin{array}{c}\text { Thickness } \\
(\mathrm{km})\end{array}$ \\
\hline Basin structure (from top): & & & \\
2.2 & 1.0 & 1.7 & 1 \\
3.3 & 1.67 & 2.0 & 1 \\
4.4 & 2.34 & 2.3 & 2 \\
5.0 & 2.84 & 2.5 & 3 \\
5.72 & 3.3 & 2.7 & 4 \\
Crustal structure (from top): & & & \\
2.8 & 1.5 & 2.5 & 0.8 \\
5.72 & 3.3 & 2.7 & 3.2 \\
6.2 & 3.58 & 2.8 & 20 \\
6.9 & 4.0 & 3.0 & 1 \\
7.8 & 4.45 & 3.4 & 5 \\
7.8 & 4.40 & 3.4 & 10 \\
7.8 & 4.35 & 3.4 & - \\
\hline
\end{tabular}

propagated along the direction of the average rake vector. The most likely seismic moment is $1.4 \times 10^{26}$ dyne-cm, as obtained from our eGf study, which is equivalent to a stress drop of about 120 bars on a fault of the above dimension. However, the seismic moment can range from 0.5 to $2.3 \times$ $10^{26}$ dyne-cm. Our results are compatible with those obtained by Wald et al. (1996) and Thio and Kanamori (1996).

\section{Acknowledgments}

We thank Craig Scrivner, Hiroo Kanamori, Chandan Saikia, and one anonymous reviewer for their reviews of the manuscript. This research was supported by SCEC, Contract No. 569933 NSF EAR89-20136. Contribution No. 5545, Division of Geological and Planetary Sciences, California Institute of Technology, Pasadena, California.

\section{References}

Aki, K. and P. G. Richards (1980). Quantitative Seismology, Theory and Methods, Chapter 2, W. H. Freeman and Company, New York.

Dreger, D. (1994). Empirical Green's function study of the January 17, 1994 Northridge, California earthquake, Geophys. Res. Lett. 21, no. 24, 2633-2636.

Dreger, D. and D. V. Helmberger (1991). Source parameters of the Sierra Madre earthquake from regional and local body waves, Geophys. Res. Lett. 18, no. 11, 2015-2018.

Hauksson, E., K. Hutton, H. Kanamori, L. Jones, and J. Mori (1994). The $M_{w} 6.7$ Northridge, California, earthquake of January 17, 1994 and its aftershocks, The 89th Annual Meeting of the Seismological Society of America, Program for Northridge Abstracts, Abstract No. 1.

Ho-Liu P. and D. V. Helmberger (1989). Modeling regional Love waves: Imperial Valley to Pasadena, Bull. Seismol. Soc. Am. 79, no. 4, 11941209.

Langston, C. (1978). The February 9, 1971 San Fernando earthquake: a study of source finiteness in teleseismic body waves, Bull. Seism. Soc. Am. 68, no. 1, 1-29.

Saikia, C. K. (1994). Modified frequency-wavenumber algorithm for regional seismograms using Filon's quadrature-modeling of $\mathrm{Lg}$ waves in North America, Geophys. J. Int. 118, 142-158.

Song, X. J. and D. V. Helmberger (1995). Broadband modeling of regional seismograms, Basin and Range crustal structure, Geophys. J. Int. (in press).

Stead, R. (1990). Finite differences and a coupled analytic technique with applications to explosions and earthquakes, Ph.D. Thesis, California Institute of Technology, Pasadena, California.

Thio, H. K. and H. Kanamori (1996). Source complexity of the 1994 Northridge Earthquake and its relation to aftershock mechanisms, Bull. Seism. Soc. Am. (in press).

Wald, D. J., T. H. Heaton, and K. W. Hudnut (1996). The slip history of the 1994 Northridge, California, earthquake determined from strongmotion, GPS, and leveling-line data, Bull. Seismol. Soc. Am. (in press).

Zhao, L. and D. V. Helmberger (1994). Source estimation from broadband regional seismograms, Bull. Seismol. Soc. Am. 84, no. 1, 91-104.

Seismological Laboratory 252-21

California Institute of Technology

Pasadena, California 91125

Manuscript received 10 May 1994. 